\title{
Designing Activated Carbons from Natural and Synthetic Raw Materials for Pollutants Adsorption
}

\author{
P.A.M. Mourão ${ }^{\text {a }}$, I.P.P. Cansado ${ }^{\text {b. P.J.M. Carrott }}{ }^{\mathrm{c}}$ and M.M.L. Ribeiro Carrott ${ }^{\mathrm{d}}$ \\ Centro de Química de Évora and Departamento de Química, Universidade de Évora \\ Rua Romão Ramalho n59, 7000-671 Évora - Portugal \\ a pamm@uevora.pt, ${ }^{\mathrm{b}}$ ippc@uevora.pt, ${ }^{\mathrm{c}}$ peter@uevora.pt, ${ }^{\mathrm{d}}$ manrc@uevora.pt
}

Keywords: Raw materials, Activated carbon, Adsorption, Organic pollutants.

\begin{abstract}
Over the last decades the literature has shown the possibility of producing activated carbons (AC) from a wide variety of raw materials, and to use them as one of the most environmentfriendly solutions for waste disposal [1]. Simultaneously, it has been shown that the adsorption of pollutants from different sources by activated carbons is one of the most efficient techniques for remediating or solving this kind of problem [2]. In this context, phenolic compounds represent one of the most important classes of pollutant present in the environment [3]. In this perspective, we present a study involving the production of AC from cork (Quercus suber L.), PEEK (polyetheretherketone) wastes or granulated recycled PET (polyethyleneterephthalate) and their applicability for the adsorption of phenolic compounds from the liquid phase. All samples were characterised in relation to their structural properties and chemical composition, by different techniques, including nitrogen adsorption at $77 \mathrm{~K}$, elemental analysis $(\mathrm{C}, \mathrm{H}, \mathrm{N}, \mathrm{O}$ and $\mathrm{S})$ and point of zero charge (PZC). The activated carbons produced demonstrated high adsorption capacities both in the gas and liquid phase as exemplified by $\mathrm{N}_{2}$ and phenolic compounds adsorption experiments. Based on the structural and chemical properties, and on the kinetic and equilibrium studies of liquid phase adsorption, it is possible to conclude that it is the porous volume of the ACs that predominantly controls the process of phenolic compounds adsorption.
\end{abstract}

\section{Introduction}

In the present days one of the greatest challenges to humanity is to diminish or remediate the pollution of the earth's environment produced by human activities [1]. Organic compound pollution has become a major concern in the production of safe drinking water and in many countries there are strict regulations that limit the concentration of these compounds. Phenolic compounds are among the most frequent contaminants of water [4]. And particularly, chlorophenol derivatives are toxic to a wide range of micro-organisms and to man, and concentrations as low as one part per thousand million can contaminate water [5]. In this work, 4-chlorophenol was chosen for investigation due to its unpleasant odour, its harmful properties against the environment and due to its wide presence.

Another very important class of pollutants is dyes that are not biodegradable. Essential sources of this pollution are petroleum refining, plastics, textile and dyeing industries. The persistent colour and the non-biodegradable nature of the spent dyebaths represent serious problems to the environment. Although the primary concern about industrial coloured effluent is its undesirable visual impact in receiving waters, a lot of wastewater from diverse sources also contains different types of phenol compounds [6].

High temperature, biodegradation, precipitation, flocculation and adsorption are some of the methods used to diminish or solve the contamination problem. On most occasions, thermal treatments present considerable emission of other hazardous compounds. The biological treatments require a long residence time for microorganisms to degrade the pollutant and they can be affected by toxicity and temperature changes. Frequently, the other techniques such as flocculation, precipitation and adsorption on activated carbon require a post-treatment step. However, between 